\title{
PRELIMINARY EXAMINATION OF BULL, RAM AND RABBIT SPERMATOZOA WITH THE STEREOSCAN ELECTRON MICROSCOPE
}

\author{
H. M. DOTT \\ A.R.C. Unit of Reproductive Physiology and Biochemistry, \\ University of Cambridge* \\ (Received 22nd June 1968)
}

The stereoscan electron microscope (Cambridge Instrument Co.) enables the surface of objects to be examined over a wide range of magnifications, but the object must be carefully washed to remove substances which might obscure its outlines, and when the object is biological the substances washed away may be an important part of the surface.

With this limitation in mind, samples of ejaculated bull and rabbit, and testicular ram spermatozoa were prepared in the following way: (1) Seminal plasma (or testicular fluid) was removed from semen by centrifuging at $20,000 \mathrm{~g}$ for $20 \mathrm{~min}$. (2) Spermatozoa were resuspended in $40.0 \mathrm{ml}$ phosphate-buffered saline $(0.125 \mathrm{M}-\mathrm{NaCl}, 0.02 \mathrm{~m}$-phosphate buffer, $\mathrm{pH} 7.4)$ and centrifuged at $1000 \mathrm{~g}$ for $10 \mathrm{~min}$; the supernatant was removed. This was repeated four times. (3) The spermatozoa were fixed by adding $0.1 \mathrm{ml}$ of sperm suspension to $0.9 \mathrm{ml}$ $2.5 \%$ glutaraldehyde at $\mathrm{pH} 7.0$ and keeping at $4.0^{\circ} \mathrm{C}$ for $1 \mathrm{hr}$. (4) The fixative was removed by centrifuging at $1000 \mathrm{~g}$ for $10 \mathrm{~min}$. The spermatozoa were resuspended in distilled water. This process was repeated twice. (5) A drop containing fixed spermatozoa in distilled water was allowed to evaporate on a glass cover slip and examined in vacuo with the stereoscan microscope.

When samples were removed and fixed at various stages of the washing procedure it was found that the fourth prefixation wash was unnecessary. In order to subject bull spermatozoa to cold shock a $1-\mathrm{ml}$ sample of bull semen was spread on the bottom of a 250-ml Erlenmeyer flask in an ice bath and left for $20 \mathrm{~min}$ before washing. Samples of fixed spermatozoa were also examined under the phase contrast light microscope.

Bull spermatozoa with intact acrosomes (Plate 1, Fig. 1) have fairly smooth heads with the suggestion of a depression just behind the tip of the acrosome and a series of depressions at the posterior border of the equatorial segment. In spermatozoa in which the acrosome is still present but not intact (Plate 1, Fig. 2), the depressions at the posterior border of the equatorial segment are more marked and the anterior border of the equatorial segment is raised. When the acrosome is lost as a result of cold shock (Plate 1, Figs. 3 and 4), the equatorial segment is raised above the level of its surroundings and a series of holes or

* Postal address: Animal Research Station, 307 Huntingdon Road, Cambridge, England. 
indentations appears at the posterior border. Ram spermatozoa also show depressions along the posterior border of the equatorial segment; in the sample examined, there was a high proportion of spermatozoa with 'knobbed' acrosomes (Plate 2, Fig. 6). In the rabbit, the equatorial segment seems to be raised in the intact spermatozoon (Plate 2, Fig. 7) but this is less obvious when the acrosome is lost (Plate 2, Fig. 8); in neither situation is there a series of depressions at the posterior edge.

Special attention was given to the cytoplasmic droplet, a structure which is situated close to the head of the spermatozoon when it leaves the testis. If found on a mature spermatozoon the droplet is most frequently situated just short of the distal end of the midpiece (Plate 2, Figs. 9 and 10). This region of the midpiece appears to be particularly susceptible to distortion, and often it is bent round a droplet. But even when the droplet has been lost, or is still close to the head, the midpiece tends to bend at this point (Plate 2, Fig. 10).

In their general appearance spermatozoa which have been prepared for examination with the stereoscan electron microscope do not differ appreciably from spermatozoa derived from the same fixed material examined with the phase contrast microscope (see insets on Plates 1 and 2). Moreover, the phase contrast image of fixed material is very similar to that of fresh, i.e. untreated, material. Nevertheless, it is possible that the drying of specimens and their examination in vacuo may have produced distortions at the surface and, consequently, some artefacts. Since, however, the various features observed in the stereoscan electron microscope were constant from spermatozoon to spermatozoon, it is probable that they do represent a characteristic of the area, even if the characteristic in fresh material is not exactly what it appears to be in fixed, dried material.

I am most grateful to the Cambridge Instrument Co. for the use of their stereoscan electron microscope and in particular to Miss C. Moss and her colleagues for expert technical assistance. 
PI.:II: I
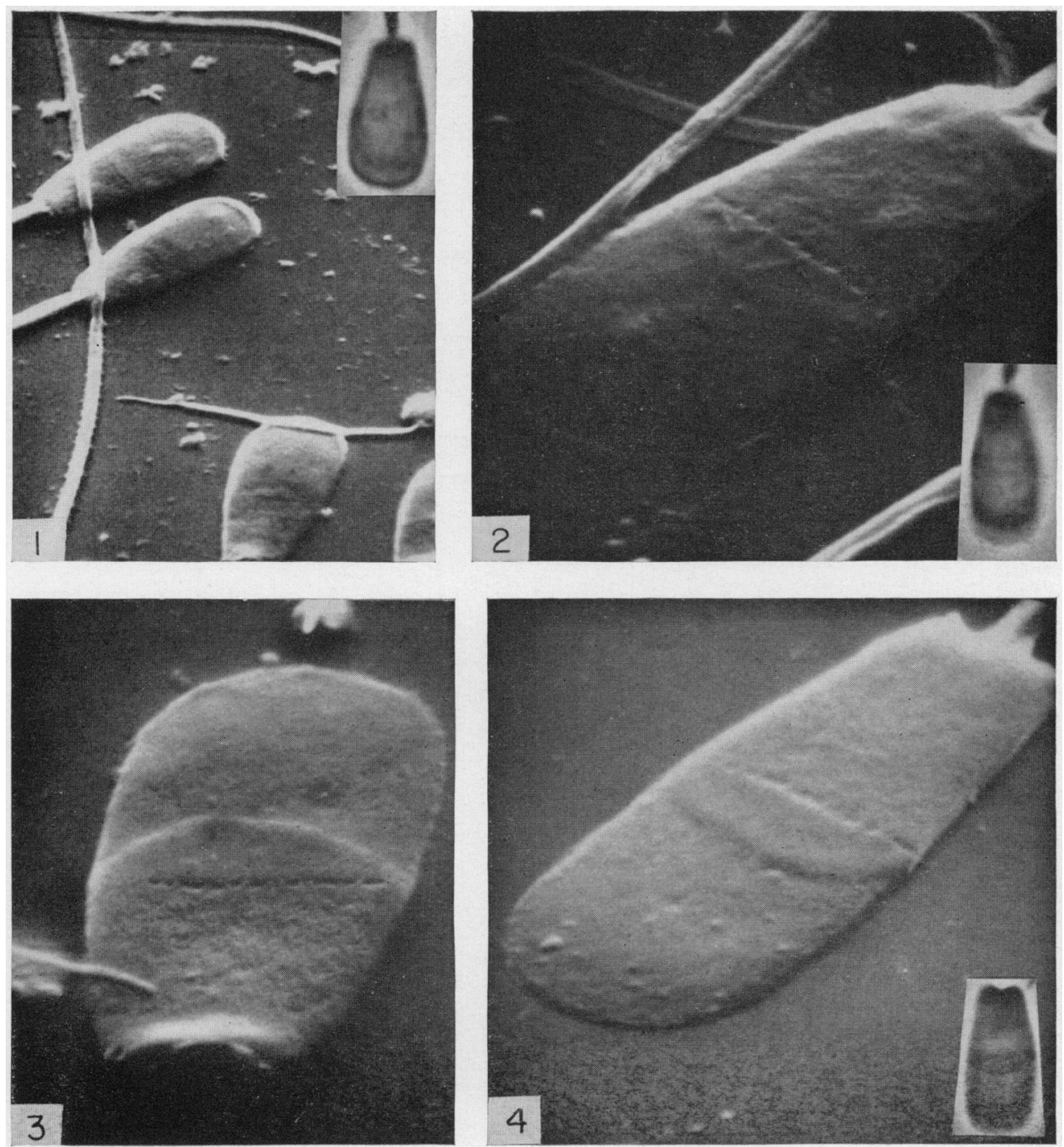

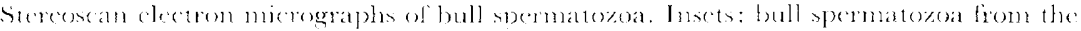

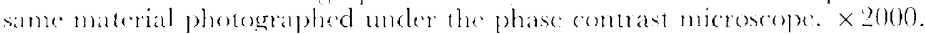

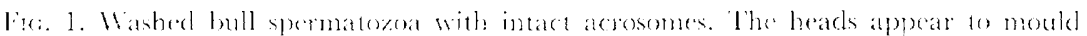

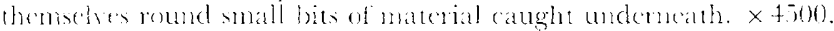

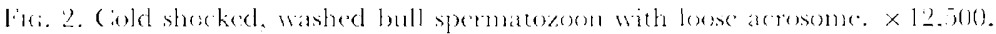

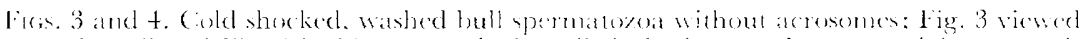

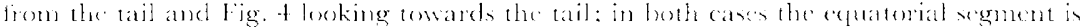

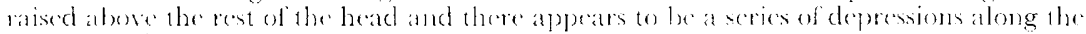
posterior edge. $\times 12.50()$. 
PI.ATE 2
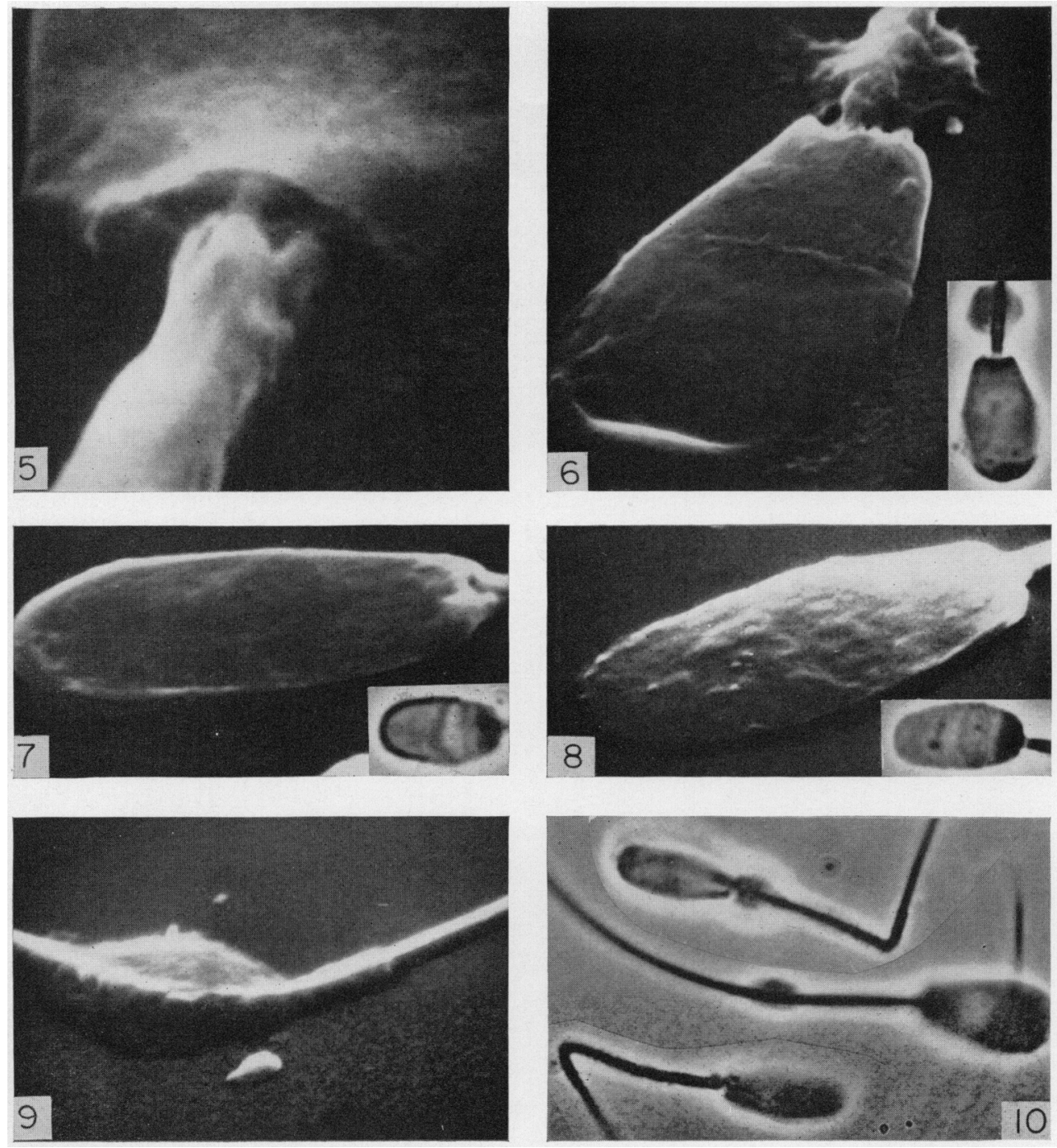

Figs, is to 9 . Stereosean electron micrographs of spermatozoa. Insets: spermatozoa fiom the sance material photographed under the phase contrast microseope $\times 2000$.

Fig. 5 . Hashed bull spermatozoon showing the expansion ol the head to accommodate the junction with the midelle piece. $\times 45,000$.

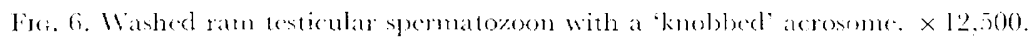

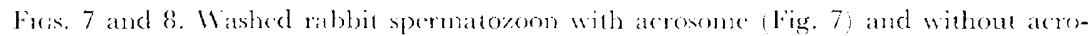
some (Fig. 8i. $\times 12$ 12.io).

Fin. 9. Nashed bull spermatomom with a cyoplasmic dropled just short of the distal end of the midpiece. $\times 15.060)$.

Fis. 10. Phase contrast photomicrograph of washed bull spematezoa showing the position of the "distal" "yoplasmic droplet and of the bend in abmormal midpieces. This is a compesite photograph of spematozoa from different parts of the same slide. $\times 2000$. 